THE KURUME MEDICAL JOURNAL Vol.13, No.3, 1966

\title{
AN AUTOPSY CASE OF VISCERAL SCLERODERMA WITH LATHAL ILEUS
}

\author{
TERUYUKI NAKASHIMA, TOYOMI TAJIRI, AND TADASHI TASHIRO
}

\author{
The Second Department of Pathology, Kurume University School of \\ Medicine, Kurume, Japan
}

MASAE SHIBATA AND HIDEO TSUJI

Takeo National Sanatorium, Takeo-shi Japan,

(Received for publication October 31, 1966)

The systemic sclerodermas are occasionally seen in various organs, especially in the heart, lungs and esophagus. They are called visceral sclerodermas or progressive systemic sclerosis $(\operatorname{Goetz}(1945))^{9)}$. The digestive systems except for esophagus are rarely involved, and when they are invaded, they usually reveal uncertain symptoms such as anorexia or digestive disturbances. Severe enteric obstruction is rarely occurs, thus we were unable to obtain any data in Japan covering the past 20 years. We would like to report an autopsy case which the victim died under the diagnosis of paralytic ileus which was determined to be a case of intestinal scleroderma by histologic examination.

Case.

Y.B., a girl 18 years of age.

Clinical History.

Chief complaint: Abdominal pain and vomiting.

Present illness: The patient felt abdominal pain and vomited 2-3 times a month for 3 months prior to admission. The pain moved from the upper abdomen to the left lower portion, but was apt to happen in the reverse order. Occasionally, the pain occured simultaneously. The symptoms gradually intensified until August 1965, when she had been diagnosed and treated as cholelithiasis by a medical practitioner. But, the pain continued, so she visited the Takeo National Sanatorium, and was admitted on September 20, 1965. At that time, she vomited yellowish watery content with bile 2-3 times a day, and also had diarrhea several times daily without bloodmingling.

Family History : Not remarkable.

Past History: She had an appendectomy 3 years ago, and contacted pneumonia about a half year ago. On that occasion, her serum revealed positive syphilitic reaction.

Social and Occupational History : She was not married and lived at her home.

Habbits : She did not drink and smoke.

Physical examination: The patient was undernurished and her face was pale and painful. Skin was dry. The conjunctivae showed no remarkable anemia and the sclerae were not icteric. The pupils were not irregular and reacted promptly against light. 
The tongue was thickly coated. The cervical lymphnodes were not palpable. The pulse was 120/min. quick and regular. Her chest was clear to percussion and auscultation. The upper abdomen was distended, tympanitic and somewhat resistant, but the muscle defence was not observed. The epigastrium and left lower region were generally tender. Her organs or tumors were not palpable. There were slight intestinal murmurs. X-ray findings of the chest were not remarkable. Scout film of the abdomen revealed the retention of a large amount of gas in the small intestine of epigastrium but the niveaus were not found and the intestinal wrinkles were not clear. E.C.G. showed depression of the ST segment (II . IIIa. aVF. $\left.V_{3} V_{4} V_{5}\right)$, flattening of the $T$ wave $(\mathrm{aVR})$ and the negative $\mathrm{T}\left(\mathrm{V}_{1} \sim \mathrm{V}_{6}\right)$.

Laboratory data at the admission: Examination of the blood disclosed 77 percent hemoglobin/Sahli, hematocrit was 34 percent, 3,740,000 red blood cells and 7,900 white blood cells with a differencial count of 70 percent segmented neutrophils, 7 percent non-segmented neutrophils, 16 percent lymphocytes, 5 percent monocytes and 1 percent eosinophils. The coagulation time was $6-12.5 \mathrm{~min}$. and the bleeding time was $2 \mathrm{~min}$. The precipitation of blood was considerably accelerated $(63 / 84 \mathrm{~mm})$. Serum protein fractions were not examined, so information on $\gamma$-globulin is not available.

Her serum showed negative Takata's reaction, Gross' reaction 1.50, bilirubin index 9.2 (Meulengracht's unit), T.T.T. 7.1, GOT $36 \mathrm{U}$, GPT $13.5 \mathrm{U}$ (Karmen's unit), and BUN was $15 \mathrm{mg} / \mathrm{dl}$. Serologic test for syphilis was positive. The stool examination was negative for occult blood and no parasites or ova were detected. Urinalysis showed $\mathrm{a}(++)$ test for albumin, $( \pm)$ test for urobilinogen and $(-)$ for sugar. Diazo reaction

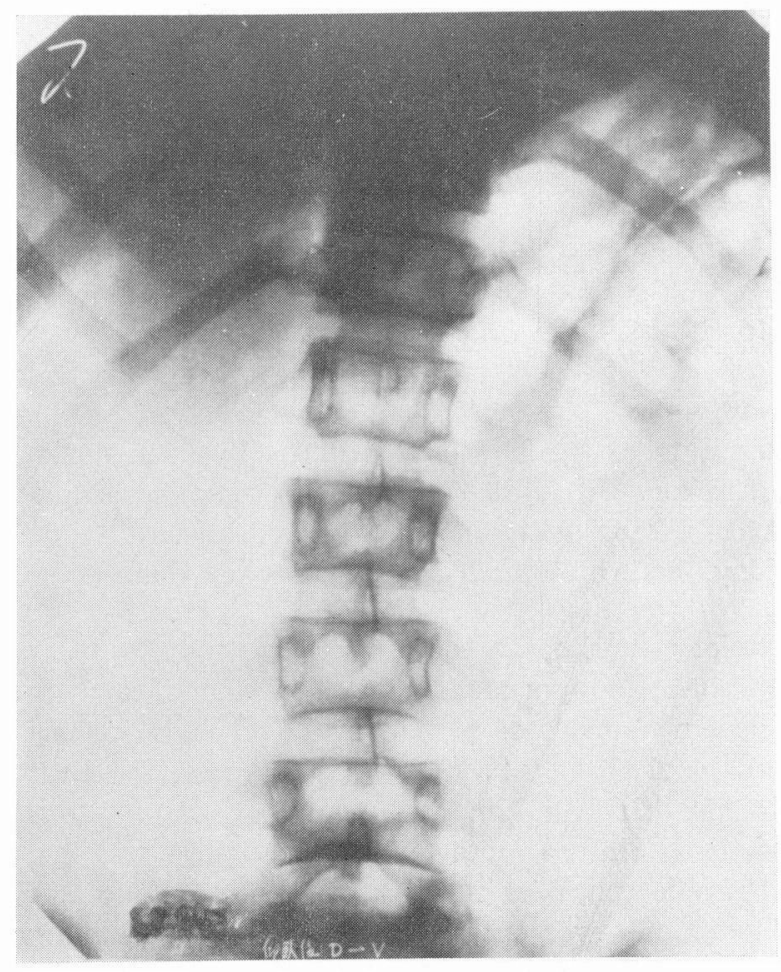

Fig. 1. Intestinal gas retention just before the laparotomy, 
was negative, diastase 64 , the sediment was loaded with hyaline and granular casts, many white blood cells, 4 red cells in a visual field and positive trichomonases.

Hospital course: The patient had been given a transfusion of glucose and Ringer's solution soon after the admission. Antibiotics were administered for 3 days. However the vomiting and abdominal pain continued. A laparotomy was performed immediately after the X-ray photographing (Fig. 1) which showed a larger amount of gas retention than before, under the diagnosis of being doubtful paralytic ileus. When the abdominal cavity was opened, a few serous ascitic fluid was observed and transverse colon and intestines were severely filled. The stomach was flaccid. The wall of intestines and colon were thick and edematous. No adhesions, bleeding or necrosis could be seen. The obvious cause of ileus was not present. The wound was closed without determining the cause.

On the fouth postoperative day, the discharge of gas and spontaneous defecation were present. The $\mathrm{X}$-ray examination of 14 th day after operation revealed the general accumulation of intestinal gas again (Fig.2), but the abdominal pains and vomiting had subsided considerably.

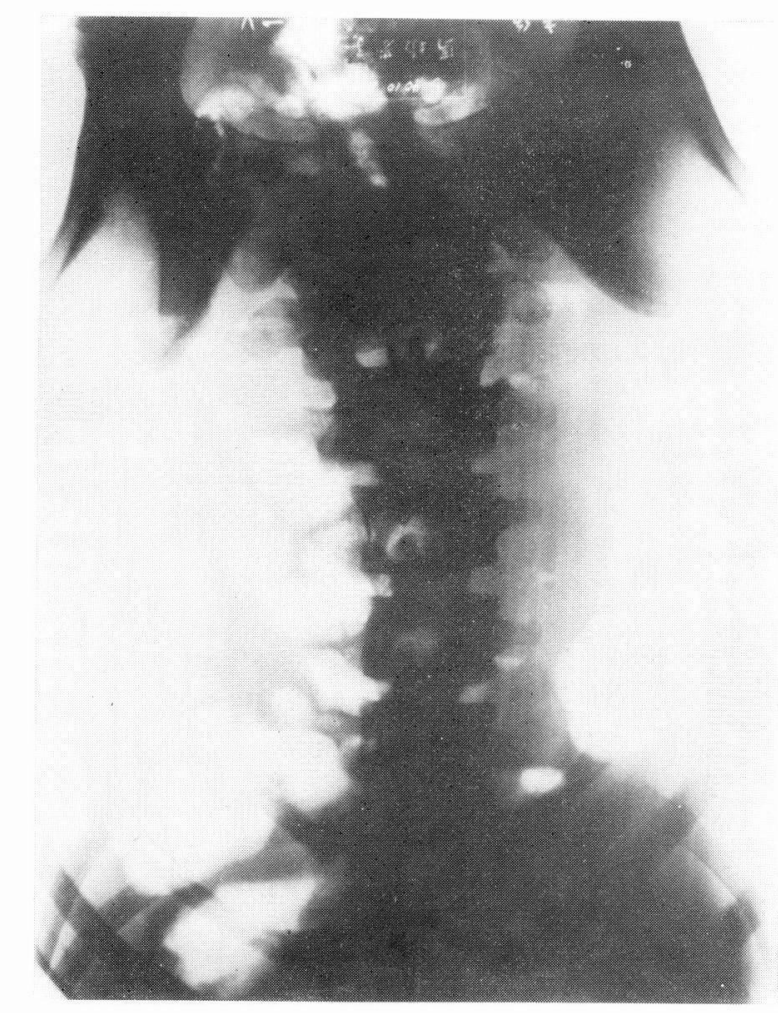

Fig. 2. The X-ray Photograph at 14 th day after operation. The accumulation of gas in the bowel reappeared.

The pain and vomiting were aggravated again about 25 days after operation, and stools were mucous and liquid. Amoeba and occult blood in the stool were 
negative. White blood cell count was 18,900. The patient was given $36 \mathrm{mg}$ of corticosteroids (decadolon) against her toxic symptoms and general signs.

Examination of the blood and urine revealed little change from that preceeding operation-slightly anemic and proteinuria. The serologic test for syphilis was now negative.

In the meantime, 40th day after operation, her face became mask-like and the difficulties of swallowing and speaking appeared. The dyspnea also could be seen, but the sclerosis of the facial skin was not noticed. In spite of our efforts, we were ineffective, and the patient died on the 43rd day after operation.

A postmortem examination was performed on November 4th 1965. The body was emaciated and anemic. The heart was hypertrophic (400gms). The left ventricular wall measured up to $17 \mathrm{~mm}$ in thickness.

Epicardium showed slight fibrous thickening. The valves and coronary arteries were not remarkable. The left pleural cavity contained approximately $700 \mathrm{ml}$ of yellowish, somewhat turbid fluid. The lower lobe of the left lung was atelectatic. There was no circumscribed lesion on the section of the lungs.

The small amount of yellow turbid ascites could be seen in the abdominal cavity.

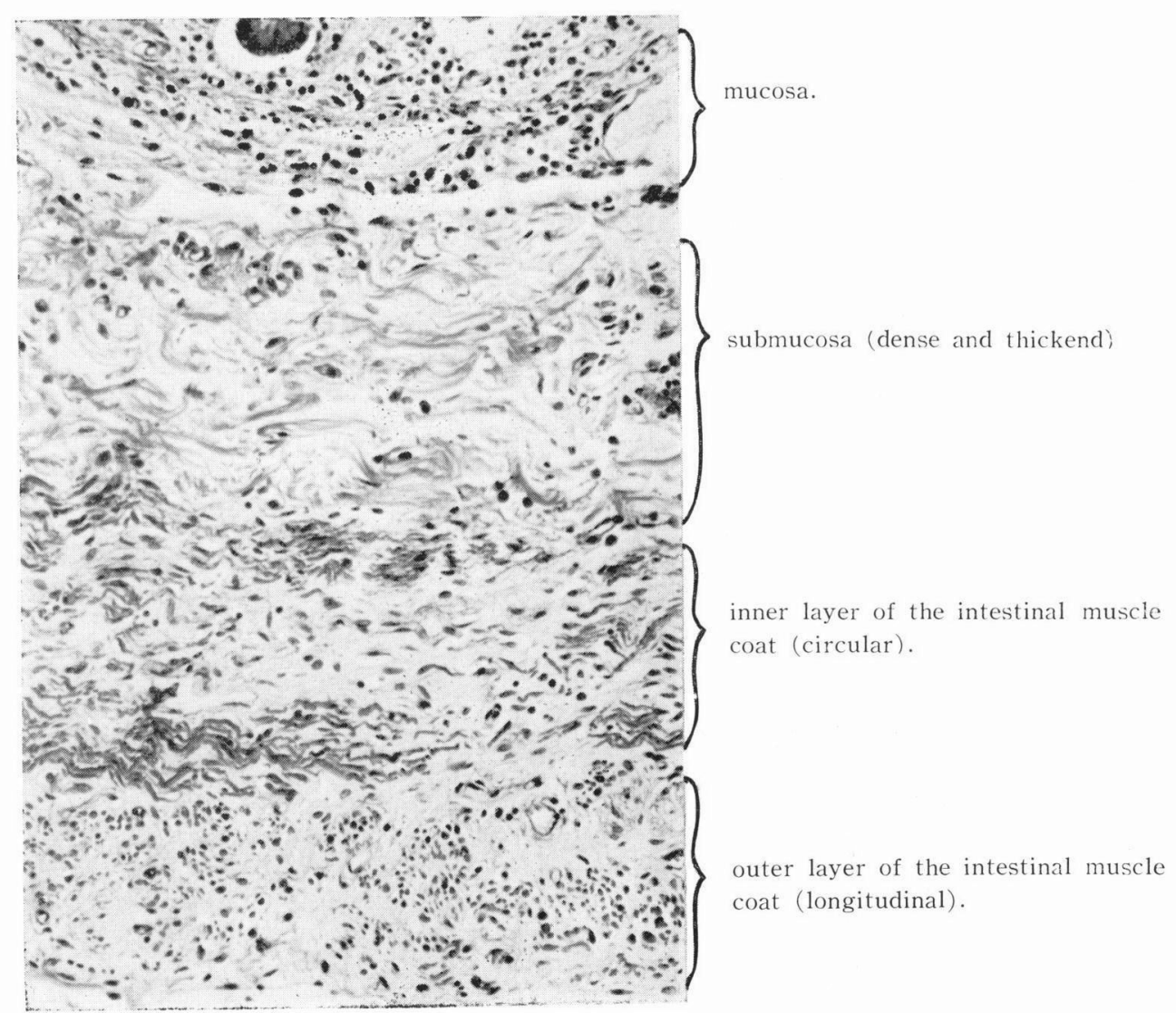

Fig. 3. Destruction and reduction of smooth muscle fibers of intestinal muscular layer, and submucosal or intramuscular fibrous proliferation can be seen. 
The intestine and colon, in general, adhered to each other with fibrous membrane and the adhesion could be separated with the fingers without difficulty. These adhesion and ascites were not detected during the operation 43 days ago.

The serous surfaces of the stomach, intestines and peritoneum were edematous and congestive. The intestinal wall became diffusely thick and taugh. It obviously seemed to restrict the intestinal peristalsis. They were also distended by a large amount of gas. No ulcers or mucosal hemorrhages could be seen in the stomach, intestines and colon. The wall of the gall-bladder was also thickened without stones or inflammation. Both kidneys revealed distinct swelling (the left kidney weighed $220 \mathrm{gms}$, and the right $250 \mathrm{gms}$ ). The spleen, $100 \mathrm{gms}$, and genital organs were not remarkable.

Histologically, intetstinal mucosae were unchanged but its muscles, especially longitudinal muscle layer, diffusely and greatly reduced (Fig.3). Many of their muscle fibers were disrupted or disintegrated, and the fibrous tissue proliferated among them. Dense connective tissue proliferation were also seen in submucosa which was remarkably widened.

There were lymphocytic infiltrations mingled with some neutrophiles in the edematous serosa. This would be a sequela of the last laparotomy.

Intestinal capillaries were dilated and occasionally showed fibrinoid change. The endothelial cells were swollen.

Pulmonary alveolar walls were diffusely but slightly thickened with prominent hyalinization of alveolar vessels. The epicardium was covered with small amount of fibrin membrane and there were some lymphocytic infiltrations beneath it. Many of the cardiac vessels had fibrinoid changes of their adventitial tissue. Cardiac muscles were hypertrophic and a microscopic localized myocarditis could de noticed by muscular destruction and inflammatory infiltration in the section (Fig.4).

Most of the renal glomeruli showed some eosinophilic homogenous thickening of

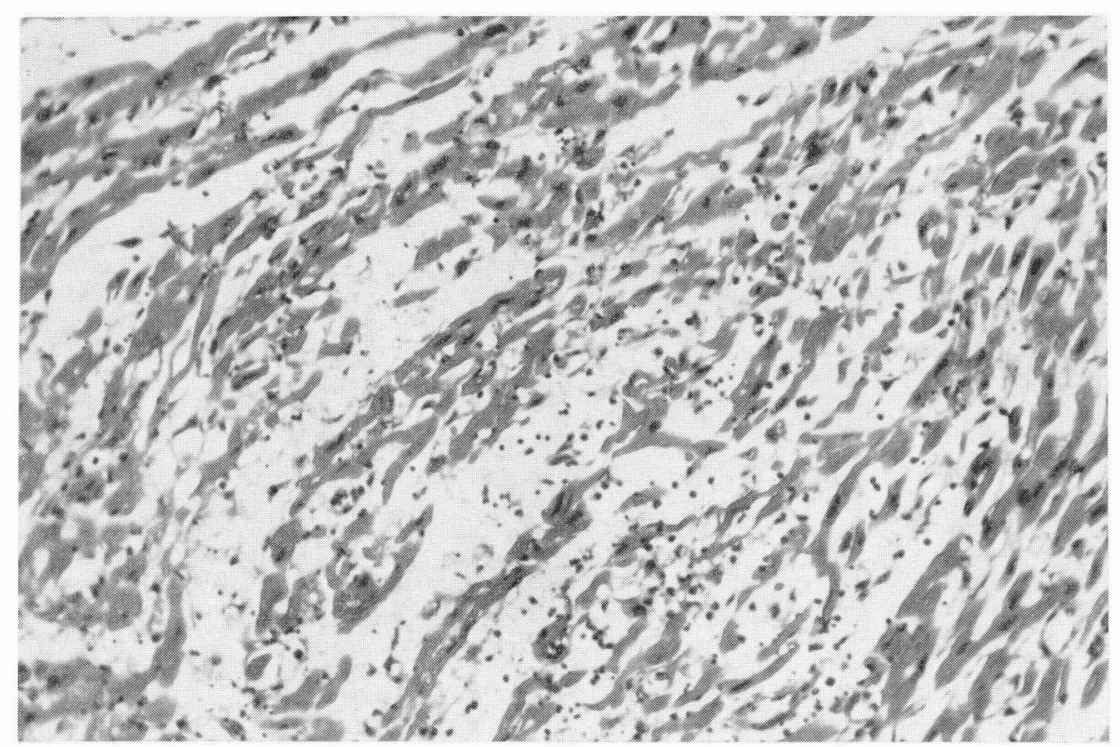

Fig. 4. A small focus of localized myocardtis. 


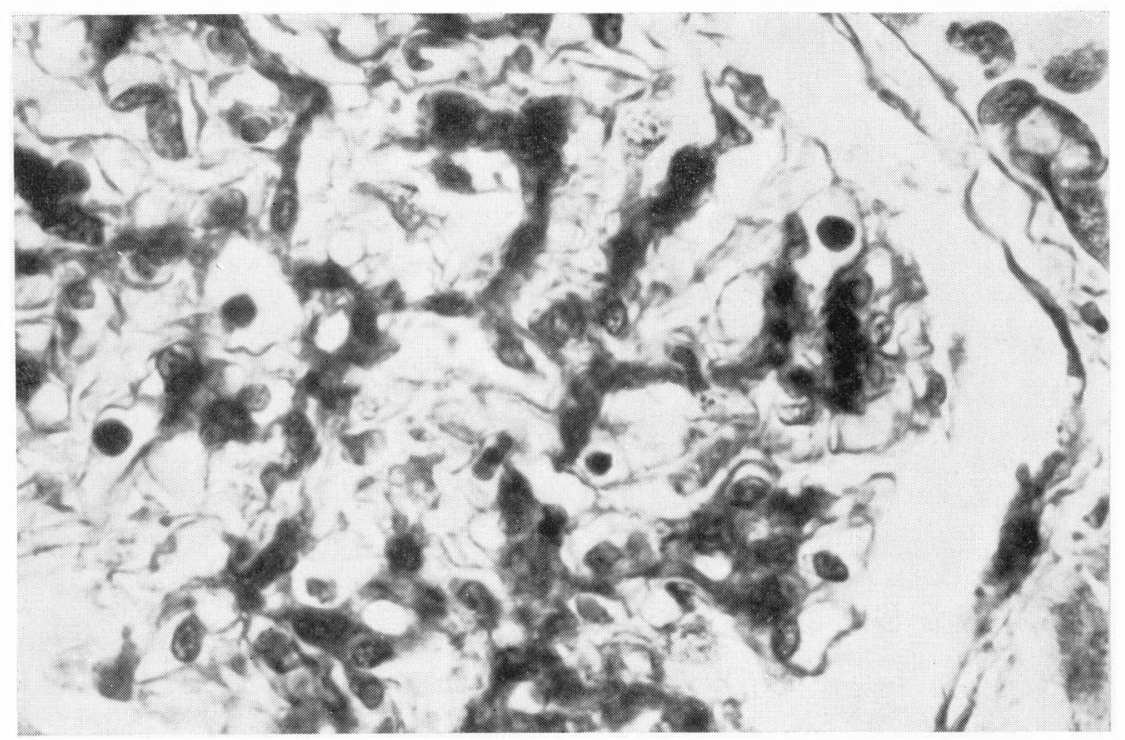

Fig. 5. The renal glomerular change resembling to so-called "wire-loop" lesion of S. L.E.

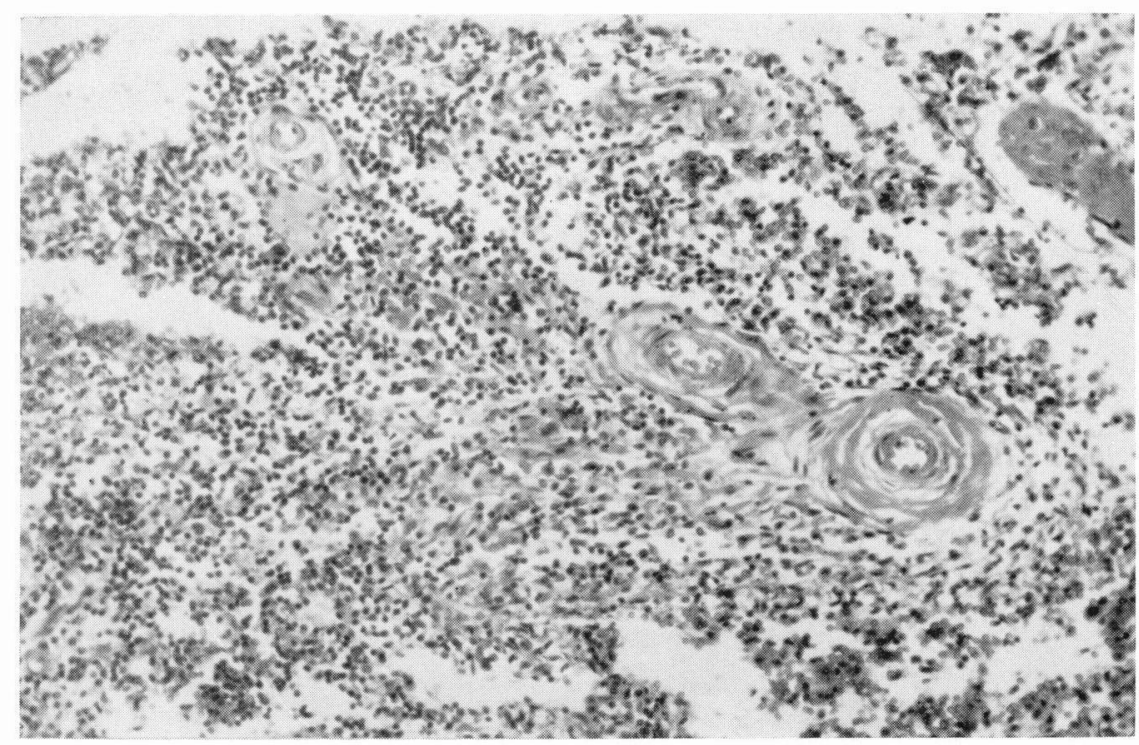

Fig. 6. The central arteries of spleen show "onion-skinning" like figure.

the basement menbranes like so-called wire-loop lesion (Fig. 5) seen in systemic lupus erythematosus (SLE). Changes similar to SLE in splenic central arteries which showed the figure of onion-skinning (Fig. 6) were detected. Fatty depositions in the liver cells were conspicuous.

We did not find any changes which should be recognized as luetic origin, such as many plasma cell infiltration or endothelial swelling and vasculitis of the small 
vessels, during our examination of the organs.

\section{DISCUSSION}

Visceral scleroderma or progressive systemic sclerosis usually involves the heart, lungs and esophagus. Piper and Helwig (1955) ${ }^{35)}$ recognized heart involvements in $99 \%$ of the autopsy cases of systemic scleroderma. He also reported that lung lesions were found in $94 \%$ of the cases and the frequency of esophageal sclerosis was $90 \%$. His ratios of visceral involvements seems to be higher than others' reporting $44-69 \%$ of the lungs (Boyd et al $(1954)^{3)}$, Leinwand et al $(1954)^{22)}$ ), and $45-69 \%$ of the esophagus (Evans et al (1954), Mahrer et al (1954)). Rossier (1954) and others believe that the lung was most frequently involved.

According to our collections of Japanese articles from 1943 to 1965 (Table 1) ${ }^{(1 \sim 40)}$, pulmonary involvement is the highest. We found 41 autopsies of this disease in Japan. The skin lesions were seen in all cases (except ours). second was the lung's (83\%). Heart and kidney were next, and both were approximately the same $(70.7 \%$ and $73.2 \%)$.

Intestinal involvements were seen in 16 cases (41.5\%), and except for 2 cases clinical symptoms of gastrointestinal series were not reported.

One of these 2 cases was ours, and the other was one reported by Mori (1959) ${ }^{25)}$ which had the symptom of ileus from the obstructive metastatic cancer of upper jejunum.

The ages of these cases were among 17 and 73 . The 30 cases $(75 \%)$ are in the $3 \mathrm{rd}$, 4 th and 5 th decades.

Females are 4 times greater than males $(32: 8$, In 1 case the sex was not recorded).

The low frequency of esophageal lesion in our statistic was somewhat unexpected. There may be some histologic oversight in esophagus during the routine autopsies when the patients did not complain of passage disturbances as did our case. Because of the lack of obvious dermal symptoms, our case was not diagnosed as a scleroderma until the histologic examination was completed. To our regret, the chance of scrutinizing the esophagus was lost. Orabona and Albano (1958) ${ }^{33)}$ referred to the importance of gastro-intestinal scleroderma without skin lesions. Abrams et al (1954) reported a case which could be diagnosed as a scleroderma after the careful histologic examination of digestive systems. Our case would correspond to it. Orabona and Albano gathered nearly 20 articles of the systemic sclerodermas complicated with enteric obstructive symptoms. They were all given laparotomy, and obstructive lesions were not detected and the patients died shortly after the operation. Our case is very similar to those described. Skouby and Teilum (1946) asserted that an operation not be performed on these patients however it will be considerably difficult for clinicians to judge their cases properly, especially when the clinical diagnosis of scleroderma has not been confirmed.

But, in general, the enteric involvement in progressive sclerosis only reveals some vague symptoms such as anorexia, abdominal discomfort, sense of fullness or constipation, and occasionally abdominal pain or diarrhea is present. The mingling of blood or fat into the feces rarely occurs, and the occurence of ileus is exceedingly uncommon, 
In Japan, our case would be the first recognized as a visceral scleroderma with the symptom of ileus directly resulted from the intestinal sclerotic changes.

This case also has the renal glomerular lesions thought of as a kind of "wire-loop", and the perivascular changes resembling the "onionskinning" of splenic central arteries. The lungs show some thickening and fibrosis of the alveolar walls similar to the other reports on this disease.

The changes in the kidney and the spleen seem to suggest the relationship with systemic lupus erythematosus as mentioned by Beigelman $(1953)^{2)}$, Mackay $(1963)^{23)}$, Fujimaki $(1962)^{5)}$ and others.

\section{SUMMARY}

Eighteen years old girl with abdominal pain and vomiting followed by the symptom of ileus died 45 days following the laparotomy.

The operation revealed no enteric obstruction or adhesion, and the cause of ileus was not detected. The autopsy showed the diffuse sclerosis of gastro-intestinal tract which could be presumed as the origin of paralytic ileus. Histologically, the sclerotic lesions were seen especially in outer muscular layer, and inner muscular coat and submucosa were also involved. There was some sclerosis in the alveolar walls, glomerular tufts and around the splenic central arterioles.

We did not clinically notice the lesions of the skin. It could be said that the cutaneous sclerosis would be very slight, if it did exist.

\section{REFERENCES}

1) BabA, M. , Matsui, T., ONo, I. AND OGAwA, S. : A case of autopsy on general scleroderma. Trans. soc. path. jap., 40, (Editio Regionalis) 80, 1952. (in Japanese)

2) Beigelman, P. M. et AL. : Progressive systemic sclerosis. New Engl. J. Med., 249, 45, 1953.

3) Boyd, J.A.ET AL. : Roentgen changes observed in generalized scleroderma report of 63 cases. Arch. int. Med., 94, 248, 1954.

4) Endo, T. , Seki, I. , Hibi, J., Ozeki, H. and Hayashi, S. : A case of diffuse scleroderma. J.J. S.Z. M. , 49, 899, 1960. (in Japanese)

5) Fujimaki, S. : Kogenbyo (Collagen disease) 1966. (in Japanese)

6) Fujimoto, Y., Yamamoto, T. and Itasaka, K. : About 2 cases of general scleroderma seen in the patients exposed to the atomic bomb at Hiroshima. J. Hiroshima Med. Ass., 15, 909, 1962. (in Japanese)

7) Fukuda, M., Kurihara, T. And Kubota, S. : A case of autopsy on scleroderma. Trans. soc. path. jap., 44, 111, 1955. (in Japanese)

8) FukuokA, Y. AND YoshiokA, S. : An autopsy case of general scleroderma complicated with malignant nephrosclerosis. Trans. soc. path. jap., 44, 111, 1965. (in Japanese)

9) Goetz, R.H. : The pathology of progressive sclerosis with special reference to the changes in the viscera. Clin. Proc., 4, 337, 1945.

10) Hasegawa, M. : A case of scleroderma that mainly revealed cardiopulmonary symptoms. Japanese Medical Jourmal, (1984), 32, 1962. (in Japanese)

11) Iijima, S. AND MidorikAwA, H. : A case of autopsy on general scleroderma. Igakuno ayumi., 40, 359, 1962. (in Japanese) 
12) Imura, H. AND HondA, T. : A case of autopsy on general scleroderma. Jap. J. Dermat. Ser. A., 73, 375, 1963. (in Japanese)

13) Irino, T., Akamatsu, T., Mito, A. and Yoshinaka, H. : A case of autopsy on general scleroderma. The Japanese Journal of Clinical Medicine., 22, 413, 1964. (in Japanese)

14) Ito, T., Sugihara, M. AND Kobayashi, T. : A case of scleroderma. Journal of transportation Medicine., 16, 128, 1962. (in Japanese)

15) Itoi, S. , Terasinima, J. And Isozai, M. : Two cases of diffuse scleroderma. J. J.S. I. M., 46, 422, 1956. (in Japanese)

16) KaKei, H. AND Ueta, H. : A case of autopsy on general sclerodorma. Acta Dermatologica. (Kyoto) 56, 90, 1961. (in Japanese)

17) Kato, M. , Otani, S. , Kawamura, S. , Kobayashi, T. and Miyata, Y. : A case of autopsy on general scleroderma. Trans. soc. path. jap., 53, 236, 1964. (in Japanese)

18) Suguro, A. , Iwata, Y. , Inoue, H. , Fukata, H. , Ueki, Y. , Mizutani, H. and Hashimoto, S. : An autopsy on general scleroderma followed by so-called tuberculous typhobacillosis in its course. The Japanese Journal of Chest Diseases., 23, 276, 1964. (in Japanese)

19) Kitano, J., Sonoda, N., Hayashi, M. , Horimi, M., Takamori, T., Shiraogawa, T. And Yокота, H. : An autopsy case of diffuse scleroderma. Associated Virilisms. Bul. Res. Inst. Diath. Med., \%, 257, 1956. (in Japanese)

20) Kobayashi, T., Kobayashi, Y., Nishihara, K. And YAmasaki, Y. : Chest X-ray findings of the diffuse sclerodermas. The Japanese Journal of Chest Diseases., 19, 413, 1960. (in Japanese)

21) Koga, S. , Kuboyama, H. and Shimokawa, Y. : A case of diffuse scleroderma or erythematodes. J. J. S. I. M. , 50, 629, 1961. (in Japanese)

22) Leinwand, I.et AL. : Scleroderma. Ann. int. Med., 41, 1003, 1954.

23) Mackay, I. R.et AL. : Autoimmune diseases. C.C. Thomas Publ., 2nd Printing 1964.

24) Matsuura S., Yuen, S., Morishita, T., Nakain, K., Wakamatsu, T. and Utsunomiya, Z. : A Necropsy Report of the scleroderma diffusa. Bull. Kobe med. coll., 16, 427, 1959. (in Japanese)

25) Mori, T. AND InOue, Y. : A case of dermal carcinoma accompanied by diffuse scleroderma. Trans. soc. path. jap. 48, 1145, 1959. (in Japanese)

26) Morita, I. AND Matsumoto, K. : Two autopsy cases of diffuse scleroderma. Trans. soc. path. jap., 47, 383, 1958. (in Japanese)

27) Nakamoто, Y. : An autopsy case of general scleroderma. Trans. soc. path. jap., 48, 20, 1958. (in Japanese)

28) NAKAmura, Y.et AL : A case of scleroderma heart disease. Naika., \%, 353, 1961. (in Japnese)

29) NAKAta, K. AND Hirayama, R. : An autopsy case of general scleroderma complicated with mycotic infection. Kitakanto Med. J., 8, 311, 1958. (in Japanese)

30) NASU, K. , I, Y., ONIShI, S. AND KAWAAI, H. : A case of autopsy on general scleroderma. Trans. soc. path. jap., 50, 128, 1961. (in Japanese)

31) Note, N. , Kubota, M. , Kusaka, J. , Yoshi, M. , Nishitsuka, Y. and Hayashi, T. : Two cases of diffuse scleroderma and their processes of treatment. Folia Endocrinologica Japonica., 29, 56, 1953. (in Japanese)

32) Ogawa, H. : A case of autopsy on general scleroderma. Kitakanto Med. J., 3, 64, 1953. (in Japanese)

33) Orabona, M.L. And Albano, O. : Systemic progressive sclerosis. Acta. Med. Scand. Supplementum., 333, 1958.

34) Otsuru, M. : Discussion in the article of Mitsuji Inoue about a case of diffuse scleroderma. Nagasaki $\operatorname{Ig} z$., 37, 424, 1962. (in Japanese)

35) Piper, W. N. And Helwig, E. B. : Progressive systemic sclerosis. Arch. Derm. a. Syph., 72, 735, 1955.

36) TAKAta, K. : A case of diffuse scleroderma. The Japanese Red Cross Medical Journal., 10, 242 , 1957. (in Japanese) 
37) Takeuchi, J., Yoshimura, K., Yokoyama, K., Kita, Y., Komura, I. AND Fukuoka, Y. : Diffuse renal lesions, especially about so-called scleroderma-kidney. The Japanese Journal of Clinical Medicine., 16, 1217, 1957. (in Japanese)

38) Takeucti, J. And Urano, Y. et al: A primary cancer of the lung happend to metastasize diffusely with complication of general scleroderma. Naika., $7,339,1961$. (in Japanese)

39) Tomimatsu, T. AND Kumagai, Z. : A case of autopsy on general scleroderma. Kurume Med. J., 15, 95, 1952. (in Japanese)

40) Tateishi, Y., Yamasaki, S., Kanatsu, I. And Tsuji, H. : A case of scleroderma. J. J.S. I. M. , 51, 297, 1960. (in Japanese)

41) TASHiro, A. AND ONODA, T. : A case of scleroderma diffusa with muscular atrophy. Tohoku Ig. z., 54, 83, 1956. (in Japanese)

42) Watanabe, K., Moriwaki, S., Matsui, Y. and Matsui, K. : Two autopsy cases of diffuse scleroderma. J. Yonago med. Ass., 11, 742, 1960. (in Japanese)

43) YAMAKAWA, K.ET AL. : Two cases of diffuse scleroderma, especially about dynamic condition of the heart and the lung. The Japanese Journal of Clinic Medicine., 17, 347, 1959. (in Japanese)

44) Yoshida, Y., Sasai, Y., Kasai, T., Makino, Y., Saito, T., Nakamura, H., Sawano, N., NAKAMURA, K. AND IshiKatA, T. : General scleroderma with pulmonary fibrosis and esophageal stenosis. The Saishin-igaku., 18, 451, 1962. (in Japanese) 
TABLE 1

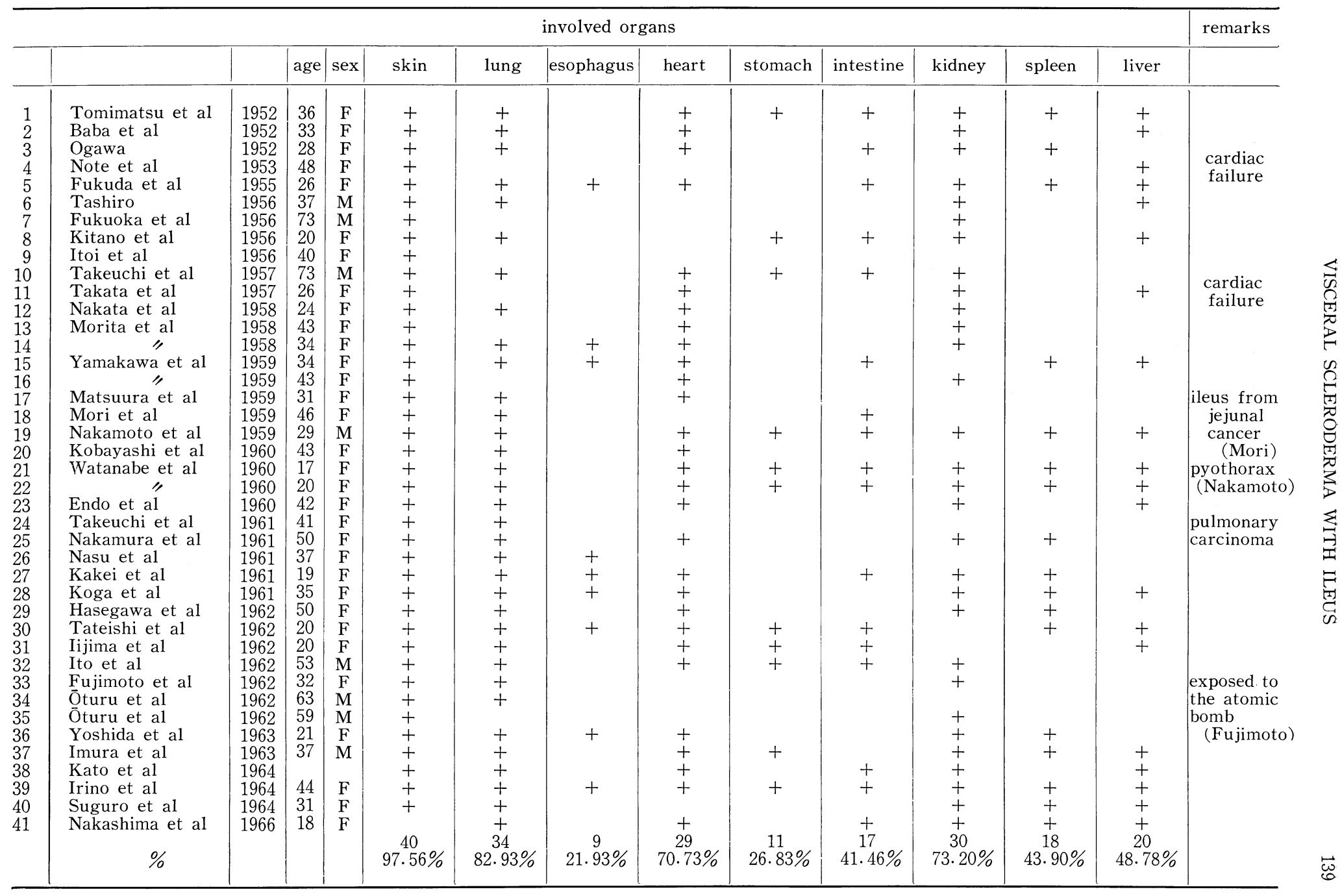

